Letrônica, Porto Alegre, v. 7, n. 2, p. 1043-1059, jul./dez., 2014

\title{
PERDER-SE NA VIAGEM, NA ESTRADA, NA HISTÓRIA: O ESTRANGEIRO EM “BEM LONGE DE MARIENBAD”, DE CAIO FERNANDO ABREU
}

\author{
LOSE YOURSELF ON THE JOURNEY, ON THE ROAD, IN THE STORY: \\ THE STRANGER IN “BEM LONGE DE MARIENBAD”, BY CAIO FERNANDO ABREU
}

Fernanda Borges Pinto*

\begin{abstract}
Resumo: Este trabalho tem por objetivo desenvolver o conceito de estrangeiro na novela "Bem longe de Marienbad", de Caio Fernando Abreu, a partir da obra de Julia Kristeva, Estrangeiros para nós mesmos, a qual explora os aspectos subjetivos e psicológicos do indivíduo que se encontra em outro país. As personagens da novela, através de seus caminhos errantes, apresentam uma nova perspectiva para a ideia de estrangeiro, uma vez que, para eles, a estrada também pode se constituir como um lar. Publicada em 1996, no livro Estranhos estrangeiros, "Bem longe de Marienbad" expõe o que é ser estrangeiro tanto no território quanto na percepção do mundo.

Palavras-chave: Caio Fernando Abreu; Estrangeiro; Teoria psicanalítica.
\end{abstract}

\begin{abstract}
This work aims to develop the concept of stranger in the novelette "Bem longe de Marienbad", by Caio Fernando Abreu, through Julia Kristeva's work, Strangers to ourselves, which explores subjective and psychological aspects of the person who is living in another country. The characters of the novelette, through their errant ways, introduce a new perspective to the idea of stranger, since the road can also be considered a home. Published in 1996, in the book Estranhos estrangeiros, "Bem longe de Marienbad" exposes what it is to be a stranger in terms of territory and perception of the world.
\end{abstract}

Keywords: Caio Fernando Abreu; Stranger; Psychoanalytic theory.

Relacionar o conceito de 'estrangeiro' à novela "Bem longe de Marienbad", de Caio Fernando Abreu, aparentemente, não é adentrar uma nova discussão acadêmica. 0 texto está presente na obra Estranhos estrangeiros, que já tem em seu título indicações quanto à abordagem desse tema. Contudo, geralmente para tratar de tal assunto,

\footnotetext{
${ }^{*}$ Mestre em Literatura Comparada pela Universidade Federal do Rio Grande do Sul (UFRGS). Doutoranda em Teoria da Literatura na Pontifícia Universidade Católica do Rio Grande do Sul (PUCRS). Bolsista CNPq. E-mail: fernanda etc@hotmail.com
} 
associa-se aos personagens de Caio as concepções de Edward Said, Stuart Hall e Homi Bhabha, teóricos ligados aos Estudos Culturais e a abordagens de cunho prioritariamente histórico-social ${ }^{1}$, o que, de certo modo, vai de encontro à natureza da narrativa em questão, que prioriza os aspectos subjetivos e psicológicos do indivíduo, estrangeiro para um novo país, mas também para si mesmo. Assim, a obra de Julia Kristeva, Estrangeiros para nós mesmos, adapta-se a este estudo, pois, mesmo enfatizando a análise psicanalítica, não esquece a análise cultural para descrever características e movimentos daquele que é estrangeiro.

Em 1992, Caio Fernando Abreu vai a Saint-Nazaire, na França, para participar da Maison des Écrivains Étrangers, programa da editora Arcane 17, que oferecia bolsas a escritores de todo o mundo, por alguns meses, para que escrevessem um livro cuja história fosse ambientada na cidade. "Bem longe de Marienbad" foi a narrativa que Caio deixou a Saint-Nazaire e que foi publicada na França em 1994 e no Brasil em 1996, somente após a morte do autor. O livro Estranhos Estrangeiros reúne quatro novelas que abordam de diversas formas a perspectiva de ser e de se sentir estrangeiro em um outro país ou no seu próprio.

Em uma entrevista filmada enquanto o autor estava em Saint-Nazaire, ele expressa sua satisfação de ser reconhecido como escritor, como um indivíduo cujo ofício é escrever.

No Brasil temos tantos problemas, é um país quase miserável, e a atividade da escrita no Brasil é quase inútil. Eu vim para cá só para escrever durante dois meses. Tive medo de não conseguir escrever. Foi uma espécie de guerra pra mim, mas eu ganhei a guerra e consegui escrever um conto que é homenagem a Saint-Nazaire, é uma história que acontece aqui, pois o papel dessa cidade na minha vida ficou muito claro: foi aqui que senti pela primeira vez a certeza plena de ser um escritor. Vim para escrever e escrevi. E digo: muito obrigado, Saint-Nazaire! ${ }^{2}$

Caio F. sempre trabalhou como jornalista para poder exercer a atividade da escrita literária, ou seja, como muitos escritores, teve de praticar outro exercício profissional por estar inserido em uma cultura que não vê ou não valoriza a escritura como profissão. Em entrevista realizada para o Instituto Estadual do Livro, afirma que

1 Conforme PIRES, Andréia Alves. O estranho estrangeiro e a poética do vestígio em "Bem longe de Marienbad". Literatura em debate. Disponível em: <http://www.fw.uri.br/publicacoes/literatura emdebate/artigos/n1_7-ESTRANHOESTRANGEIRO.pdf>. Acesso em: 2 fev. 2014.

2 Depoimento retirado do filme CAIO F. do Programa Nacional de DST e Aids do Ministério da Saúde. 
“O escritor brasileiro é um escritor de fim de semana, feriados e horas vagas” (1988, p. 4), exatamente por ter de ocupar-se majoritariamente com atividades que não incluem a literatura. Desse modo, além de representar a satisfação pessoal do autor, a temporada em Saint-Nazaire e o texto dela resultante representam também o reconhecimento de sua obra e a concretização de um ideal para muitos escritores. "Bem longe de Marienbad" é, portanto, fruto da maturidade literária de Caio Fernando Abreu e de sua breve estada na Pasárgada dos escritores.

Na escolha da epígrafe da novela, o autor apresenta a natureza da narrativa e de seus personagens.

Na epígrafe a este volume, emprestada a Miguel Torga, lê-se: "Pareço uma dessas árvores que se transplantam,/ que têm má saúde no país novo, mas que morrem se voltam à terra natal." Os personagens de Caio conservam esse desvio original, esse perder-se "no país novo", essa eterna condição de gauche, de estranho e de estrangeiro, daquele que não pode adaptar-se nem ceder nem vicejar por completo. (PEN, 2006, p. 15)

As palavras de Miguel Torga revelam que, mais que estrangeiro em outro país, somos estrangeiros em nossa própria terra, porque somos estrangeiros para nós mesmos, como afirma Julia Kristeva. A "náusea" permanece, próximos ou distantes do que chamamos "lar". Portanto, para analisar a novela "Bem longe de Marienbad", é necessário abordar discussões de cunho psicológico e psicanalítico, em alguns momentos, uma vez que a condição de estrangeiro dos personagens da novela é dupla: são estrangeiros tanto no território quanto na percepção do mundo.

Julia Kristeva em Estrangeiros para nós mesmos realiza um panorama histórico sobre a condição do estrangeiro, sobre como ele foi visto socialmente, desde a Antiguidade Clássica até quase o final do século XX, localizando já na designação de "bárbaros", aqueles que não eram gregos, a valorização das diferenças de pertencimento e origem. Além disso, aborda conceitos jurídicos que norteiam tal concepção, pois, segundo a lei, o estrangeiro é "aquele que não tem a cidadania do país em que habita" (KRISTEVA, 1994, p. 47). Assim, o próprio estatuto jurídico determina a conotação negativa do estrangeiro, estabelecendo um paradoxo social.

Se a regulamentação política ou a legislação em geral definem a nossa maneira de colocar, modificar e eventualmente melhorar o estatuto dos estrangeiros, elas também formam um círculo vicioso, pois é precisamente na visão delas que existem estrangeiros. De fato, sem grupo social estruturado em torno de um poder e dotado de uma legislação, não haveria essa exterioridade, geralmente 
vivida como desfavorável ou pelo menos problemática, que o estrangeiro representa. (KRISTEVA, op.cit., p. 101)

Do mesmo modo, a autora discute a ideia dos direitos do homem ou do cidadão, uma vez que essa simples mudança vocabular acarreta inclusões e exclusões.

(...) somos mais ou menos homens à medida que somos mais ou menos cidadãos e, que aquele que não é um cidadão não é inteiramente um homem. Entre o homem e o cidadão, uma cicatriz: o estrangeiro. Será ele inteiramente homem se não é cidadão? Não gozando dos direitos de cidadania, possui os seus direitos de homem? (KRISTEVA, op.cit., p. 102-103)

E são ainda tais aspectos jurídicos universais e também os específicos de cada nação que contribuem para muitos problemas enfrentados contemporaneamente por indivíduos que se aventuram por outros países. Com frequência temos acesso a informações divulgadas pelos meios de comunicação sobre as dificuldades de entrada, de saída e de circulação encaradas por estrangeiros em muitos locais. Entraves políticos, religiosos, culturais e jurídicos fazem com que ainda existam muitas barreiras contra aquele que não pertence ao solo que habita. Contudo, Kristeva vislumbra uma tentativa de coesão, a partir da aceitação de pressupostos psicanalíticos e políticos na sociedade contemporânea, ao final de sua obra.

Uma comunidade paradoxal está surgindo, feita de estrangeiros que se aceitam na medida em que eles próprios se reconhecem estrangeiros. A sociedade multinacional seria assim o resultado de um individualismo extremo, mas consciente de suas perturbações e dos seus limites, um individualismo que reconhece na ajuda mútua as suas fraquezas, uma fraqueza cujo outro nome é a nossa estranheza radical. (KRISTEVA, op.cit., p. 205)

Tal retomada histórica e jurídica é acompanhada de uma abordagem psicanalítica, que considera os conceitos de Freud de heimlich e unheimlich como norteadores para a compreensão da dimensão psicológica de ser estrangeiro. A partir de um estudo semântico dos adjetivos alemães heimlich e unheimlich, Freud expõe que o familiar e o insólito convivem e que:

Essa imanência do sobrenatural no familiar é considerada como uma prova etimológica da hipótese psicanalítica segundo a qual "o sobrenatural" é essa verdade particular da coisa assustadora que remonta ao há muito já conhecido, há muito já familiar, o que confirma para Freud o propósito de Schelling segundo o qual chama-se de "unheimlich tudo o que devia permanecer em segredo, na sombra, e que saiu dela." (KRISTEVA, 1994, p. 192) 
Freud, em seu ensaio de 1919, explicita que não é elucidativa a perspectiva de Jentsch sobre "o estranho" de que o sentimento de estranheza diz respeito a uma incerteza intelectual, ou seja, de que consideramos estranho aquilo que não sabemos como abordar. Em seguida, o psicanalista busca os conceitos de 'familiar' e de 'estranho', ou 'assustador', em diversas línguas a fim de perceber as nuanças entre as definições apresentadas. Analisando a língua alemã, Freud destaca que os conceitos heimlich e unheimlich, os quais deveriam ser opostos, encontram um significado comum, a ideia de 'secreto', de 'oculto'. Embora a palavra heimlich seja mais utilizada significando 'agradável' e 'familiar', ela é ambivalente, pois vai ao encontro de seu oposto, que está oculto nela mesma. Dando continuidade à discussão, o texto utiliza-se da narrativa $O$ homem da areia, de E.T.A. Hoffmann, para ilustrar suas acepções e desenvolver as ideias de 'duplo' e de recalque a partir de impulsos reprimidos durante a infância. Porém, não é esta perspectiva que cabe desenvolver aqui, e sim as relações intrínsecas entre aquilo que é íntimo e agradável e aquilo que está à sombra, oculto no que nos é familiar.

Desse modo, aplicando as reflexões de Freud, muitas vezes consideramos "estrangeiro" aquilo que de nós reconhecemos nos outros, uma vez que a constituição da identidade dá-se pela alteridade. Unheimlich, sobrenatural, insólito, estranho, gauche, termos que representam aquilo que o ser humano ainda tem dificuldade de apreender e de conceituar, mas que indicam tentativas de compreensão do outro e de nós mesmos. Kristeva acrescenta ainda, a partir da definição de "estranho" de Freud que, se o "estrangeiro" nos habita internamente, logo somos todos estrangeiros e, ao mesmo tempo, não há estrangeiros.

(...) o estrangeiro não é nem uma raça nem uma nação. (...) Inquietante, o estranho está em nós: somos nós próprios estrangeiros - somos divididos. (...) O meu mal-estar em viver com o outro - a minha estranheza - repousa numa lógica perturbada que regula esse feixe estranho de pulsão e de linguagem, de natureza e de símbolo que é o inconsciente, sempre já formado pelo outro. É por desatar a transferência - dinâmica maior de alteridade, do amor/ódio pelo outro, da estranheza constitutiva do nosso psiquismo - que, a partir do outro, eu me reconcilio com a minha própria alteridade-estranheza, que jogo com ela e vivo com ela. (...) Como poderíamos tolerar o estrangeiro se não nos soubermos estrangeiros para nós mesmos? (KRISTEVA, op.cit., p. 190-191)

A partir dessas concepções, parte-se para a análise do texto de Caio Fernando Abreu, considerando primeiramente a ideia convencional e pragmática de ser 
estrangeiro (indivíduo distante de seu país), para adentrar logo após em outros conceitos.

Em "Bem longe de Marienbad", o personagem-narrador vai à França para encontrar $\mathrm{K}$, que o estaria esperando na estação de trem. Após um período de afastamento, o personagem exprime sua ansiedade pelo reencontro, que se revela incerto e difuso. A atmosfera de incerteza instaura-se no texto desde o princípio, a partir das quatro narrações da chegada do personagem, as quais apresentam variações de horário e de perspectiva do narrador na descrição da estação. Tais possibilidades ilustram a expectativa frustrada por não haver ninguém a sua espera. No quarto relato de chegada do personagem, há menção à característica transitória da viagem deste estrangeiro.

\begin{abstract}
São muito mais de oito horas da noite, talvez nove, meu relógio foi roubado numa aldeia africana ou numa metrópole da América do Sul. Não lembro, não sei. $\mathrm{K}$ não veio, não veio ninguém e ninguém mais poderia vir além dele. Fico tentado a dar a volta agora, em direção a Amsterdã, Katmandu ou Santiago de Compostela, mas sei que $\mathrm{K}$ está aqui, nesta cidade do Norte, e eu preciso encontrá-lo. Há um hotel na minha frente. Jogo a mochila nas costas e penso: sempre haverá um hotel ao alcance do olho e das pernas de alguém perdido, aqui ou em qualquer outro lugar do planeta, e isso sempre deve ser também uma espécie de solução, mesmo provisória. Como os próprios hotéis estão aí afinal para isso mesmo: o provisório. (ABREU, 2006, p. 27)
\end{abstract}

A natureza provisória dos hotéis, observada pelo personagem, é uma das características do estrangeiro. Do mesmo modo como há aqueles que deixam a sua pátria para viver em outra, há aqueles que habitam transitoriamente diversos lugares, como é o caso do narrador, pois esta não é sua primeira busca por K e tampouco sua primeira viagem com esse objetivo. Segundo Kristeva (1994), o estrangeiro vive em um estado "transitório perpétuo", que se constitui como uma felicidade paradoxal, uma vez que a necessidade de deslocamento, de busca por um "espaço de um infinito prometido" assola-o ciclicamente.

Após deixar a estação e jantar em um hotel, o personagem sai pelas ruas de SaintNazaire em busca do endereço de K. $\mathrm{O}$ frio, a escuridão, a atmosfera sinistra do porto à noite aumentam ainda mais a expectativa do reencontro. Supondo o que K poderia pensar ao encontrá-lo, o personagem revela novamente a perspectiva nebulosa de sua viagem: “(...) sem saber ao certo se faço parte de um sonho que não estava sonhando ou de uma realidade que ele mesmo inventou, tão distraído que depois esqueceu ou teve preguiça de esperar que acontecesse" (ABREU, 2006, p. 32). Desse modo, os motivos de 
sua ida à França são questionados pelo leitor, pois tal procura ganha caráter efêmero e onírico, da mesma forma como a existência de $\mathrm{K}$, uma vez que ao encontrar finalmente o endereço, não há ninguém no apartamento. Mesmo assim, o personagem consegue entrar, a porta está aberta e tudo parece organizado e vazio, sem muitos vestígios da presença de alguém. Ao entrar em um dos quartos, reconhece a letra de $\mathrm{K}$ em algumas cartas e anotações, além de se interessar por recortes de jornais e por outros objetos a ele atribuídos.

Entre uma das anotações de $\mathrm{K}$, está um trecho de Reinaldo Arenas ${ }^{3}$, do livro Méditations de Saint-Nazaire. "Aún no sé si este es el sitio donde yo pueda vivir. Talvez para un desterrado - como la palabra lo indica - no haya sitio en la tierra. Solo quisiera pedirle a este cielo resplandeciente y a este mar, que por unos días aún podré contemplar, que acojan mi terror." (ABREU, 2006, p. 38) 0 trecho de Reinaldo Arenas revela, mesmo que indiretamente, a perspectiva de K sobre sua condição de estrangeiro, de homem sem raiz, sem lar e sem a possibilidade real de encontrá-lo. A marca intertextual expõe com profundidade e concisão os sentimentos dos personagens, sem que a narrativa explore ou desenvolva as palavras de Arenas. A ausência de comentários na novela quanto ao trecho mostra que não é preciso prolixidade para que desvelemos o interior do personagem-narrador e de K. Além disso, tal referência externa sintetiza a concepção de Kristeva de que se nos tornamos estrangeiros em um outro país é porque já o somos por dentro, ou seja, de que a impossibilidade de adaptação e de plena identificação e pertencimento é uma característica inerente ao ser humano. Porém tais características aplicam-se também ao homem cosmopolita, cuja cidadania global e difusa revela a distância de ideias patrióticas ou nacionalistas: "Ele é estrangeiro, é de parte alguma, de todo lugar, cidadão do mundo, cosmopolita" (KRISTEVA, 1994, p. 36).

Michel Foucault, em As palavras e as coisas, (1999) acrescenta à discussão a ideia de que o homem é um ser sem origem, uma vez que, por mais que se busque sentidos e indícios, não é possível reconstituir uma identidade "humana" comum, “(...) o homem é aquele 'que não tem pátria nem nada', aquele cujo nascimento jamais é acessível porque jamais teve 'lugar'” (p. 458). Desse modo, a busca por raízes e origens apresenta-se como

\footnotetext{
${ }^{3}$ Reinaldo Arenas também participou do programa da Arcane 17, mas ficou apenas uma semana em Saint-Nazaire.
} 
uma necessidade primeva ao mesmo tempo que infinita, pois nunca haverá um fim comum, apenas soluções individuais para questionamentos eternos. Os personagens da narrativa lidam com a consciência de sua condição humana de estrangeiro a partir da aceitação de tal busca eterna. Ambos sabem que a procura incessante um pelo outro e, assim, a procura pela fixação de raízes através do encontro afetivo, são movimentos que alimentam a esperança de realização, ou seja, são formas de felicidade paradoxal. A epígrafe da novela, uma citação de Camille Claudel em carta a Rodin - mencionada por Caio também na crônica "Existe sempre alguma coisa ausente", em que esclarece as relações intertextuais da obra - revela, de certo modo, um sentimento-pensamento comum a muitas pessoas, universal na medida em que todo ser humano é um "Don Juan", por sempre buscar o que lhe falta. "Il y a toujours quelque chose d'absent qui me tourmente", afirma Camille Claudel, Rodin, Caio Fernando Abreu, K, nosso narradorviajante, quem escreve e quem lê.

Imerso nas anotações e recortes de K, o narrador-personagem encontra uma página solta, que explica o desencontro.

Este é o trigésimo dia. O ciclo está completo e não encontrei o Leopardo dos Mares. Já não sei ao certo se alguém me contou, se leram nas cartas, nas runas, mas estava certo de que ele estaria aqui e só por isso vim. Procurei-o no porto, nos cafés, na praia, pelas esquinas e barcos. Olhei tudo e todos muito atentamente. Sei que o identificaria por aquela tatuagem no braço esquerdo um leopardo dourado saltando sobre sete ondas verdes espumantes. E mesmo que fizesse frio e eu não pudesse ver seus braços, reconheceria de longe seus olhos de jade. E, se usasse óculos escuros, eu assobiaria aquela canção até que me escutasse. Sem ele, não vejo sentido em continuar nessa cidade. Que todos me perdoem, mas escrever agora é recolher vestígios do impossível. Para encontrá-lo, e isso é tudo o que me importa, eu parto. (ABREU, op. cit., p. 41)

Quando a busca pela identificação e pelo pertencimento parece chegar ao fim, ela está apenas começando. Ambos os personagens estão à procura um do outro, porém, para que o encontro realmente se concretize, é necessário que um deles se permita ser encontrado. K não espera a chegada do narrador, pois ele também precisa buscar uma origem e não esperar que a origem chegue até ele. Adiar o encontro é suspendê-lo à eternidade, às diversas possibilidades de caminhos e viagens. A procura que adia o encontro é um modo de prolongar a condição de estrangeiro, a condição de liberdade, mas também de solidão, pois segundo Kristeva: “O encontro equilibra o nomadismo" (p. 
18). Logo, a partida de $\mathrm{K}$ é um meio de não fixar raízes através do afeto, de entregar-se à liberdade solitária dos viajantes.

O silêncio evidencia-se na novela de Estranhos estrangeiros. A ausência de diálogos no texto bem como a ausência da descrição de um passado comum entre K e o narrador são marcas de um não-dito que expõem o leitor a dúvidas e suposições. Além disso, o silêncio também é resultante dos desencontros entre os personagens, uma vez que, segundo Lea Masina, "A barreira que separa e obstrui as trocas afetivas certamente é a mesma que transforma as personagens em nômades permanentes.” (1998, p. 178) Silenciar, pois, representa a constante busca pela possibilidade do diálogo, da comunicação, que, se acontecesse, poderia revelar-se inócua, talvez decepcionante, ou simplesmente supérflua.

Em carta a Maria Adelaide Amaral, de 29 de dezembro de 1992, Caio Fernando Abreu conta à amiga que havia terminado o texto para a Maison des Écrivains Étrangers, novela que se chamava "O leopardo dos mares", com o subtítulo em francês de "Journal d'une ville sinistrée". Porém, na versão final do texto, tal subtítulo foi retirado e o título modificado. A menção à ville sinistrée ficou restrita ao corpo do texto, bem como a menção ao Leopardo dos Mares. $\mathrm{O}$ apelido dado ao narrador por K, como título da novela, representaria a confirmação dos encontros e desencontros das personagens, sem estabelecer dúvidas quanto à veracidade e à confiabilidade das palavras do narrador. Ao optar por "Bem longe de Marienbad" como título do texto, o autor revela a incerteza e a inconstância das possibilidades de encontro entre os dois viajantes, perspectiva que "O leopardo dos mares" não conferiria.

0 título da novela nos remete à atmosfera francesa por ser um trecho da música Marienbad, composta por François Wertheimer e pela famosa cantora francesa Barbara, e que está presente no disco La Louve, de 1973. A canção retrata uma história de amor interrompida pelo passar do tempo. A situação descrita pelos versos é uma lembrança do eu-lírico e ambienta-se em um castelo com jardins, arabescos e estátuas, em Marienbad.

\footnotetext{
Marienbad

Sur le grand bassin du château de l'idole, Un grand cygne noir portant rubis au col, Dessinait sur l'eau de folles arabesques, Les gargouilles pleuraient de leurs rires grotesques, Un Apollon solaire de porphyre et d'ébène,
} 
Attendait Pygmalion, assis au pied d'un chêne,

Je me souviens de vous,

Et de vos yeux de jade,

Là-bas, à Marienbad,

Là-bas, à Marienbad,

Mais où donc êtes-vous?

Où sont vos yeux de jade,

Si loin de Marienbad,

Si loin de Marienbad,

Je portais, en ces temps, l'étole d'engoulevent, Qui chantait au soleil et dansaient dans les temps, Vous aviez les allures d'un dieu de lune inca, En ces fièvres, en ces lieux, en ces époques-là, Et moi, pauvre vestale, au vent de vos envies, Au cœur de vos dédales, je n'étais qu'Ophélie,

Je me souviens de vous,

Du temps de ces aubades, Là-bas, à Marienbad, Là-bas, à Marienbad, Mais où donc êtes-vous? Vous chantez vos aubades, Si loin de Marienbad, Bien loin de Marienbad,

C'était un grand château, au parc lourd et sombre, Tout propice aux esprits qui habitent les ombres, Et les sorciers, je crois, y battaient leur sabbat, Quels curieux sacrifices, en ces temps-là, J'étais un peu sauvage, tu me voulais câline, J'étais un peu sorcière, tu voulais Mélusine,

Je me souviens de toi

De tes soupirs malades, Là-bas, à Marienbad,

A Marienbad,

Mais où donc êtes-vous?

Où sont vos yeux de jade,

Si loin de Marienbad,

Bien loin de Marienbad,

Mais si vous m'appeliez, un de ces temps prochains, Pour parler un instant aux croix de nos chemins, J'ai changé, sachez-le, mais je suis comme avant, Comme me font, me laissent, et me défont les temps, J'ai gardé près de moi l'étole d'engoulevent,

Les grands gants de soie noire et l'anneau de diamant,

Je serai à votre heure,

Au grand château de jade,

Au cœur de vos dédales,

Là-bas à Marienbad,

Nous danserons encore

Dans ces folles parades,

L'œil dans tes yeux de jade,

Là-bas, à Marienbad, 
Avec tes yeux de jade, Nous danserons encore, Là-bas, à Marienbad, Là-bas, à Marienbad, Mais me reviendras-tu? Au grand château de jade, A Marienbad. ${ }^{4}$

\title{
A separação vivida pelas personagens da canção é a mesma vivida pelas personagens de "Bem longe de Marienbad", de Caio Fernando Abreu. 0 próprio título da novela é um trecho da música, "Bien loin de Marienbad", o que demonstra a homenagem aos versos de Barbara e F. Wertheimer e o diálogo entre as obras. Além disso, a indicação à canção consta no desfecho da narrativa.
}

\author{
Depois que o trem dobra a primeira curva e me sinto completamente à vontade, \\ abro o envelope que trouxe comigo. Dentro, numa folha de papel arrancada de \\ um bloco, igual àquela outra, $\mathrm{K}$ copiou algumas linhas que parecem versos de \\ uma canção francesa que conheço muito bem. Tão bem e há tanto tempo que, \\ enquanto leio, todo o resto me volta à memória, e cantarolo com facilidade: \\ Je me souviens de vous, \\ Et de vos yeux de jade, \\ Là-bas, à Marienbad, \\ Là-bas, à Marienbad, \\ Mais où donc êtes-vous? \\ Où sont vos yeux de jade, \\ Si loin de Marienbad, \\ Si loin de Marienbad.
}

\begin{abstract}
${ }^{4}$ Tradução da canção Marienbad: Sobre o grande lago do castelo do ídolo/ Um grande cisne negro, usando rubis no pescoço/ desenha sobre a água loucos arabescos/ Gárgulas choram seus risos grotescos/ Um Apolo solar de pórfiro e ébano espera/ Pigmaleão, sentado ao pé de um carvalho/ Eu me lembro de você/ e de seus olhos de jade/ Lá, em Marienbad/ Lá, em Marienbad/ Mas, então, onde está você?/ Onde estão seus olhos de jade,/ Tão longe de Marienbad/ Tão longe de Marienbad/ Eu usava, naquele tempo, uma estola de plumas/ de um pássaro que cantava ao sol e dançava no tempo/Você tinha a aparência de um deus inca da lua/ Naquelas exaltações, naqueles lugares, naquelas épocas/ E eu, pobre vestal, à disposição de suas vontades/No coração de seus labirintos, eu era apenas uma Ofélia/ Eu me lembro de você/ Do tempo dos alvoreceres/ Lá, em Marienbad/ Lá, em Marienbad/ Mas, então, onde está você?/Onde você canta seus alvoreceres?/ Tão longe de Marienbad./Bem longe de Marienbad/ Era um grande castelo, em um jardim soturno e sombrio/ Muito propício aos espíritos que habitam as sombras/ E as bruxas, eu creio, ali celebravam seus rituais/ Que curiosos sacrifícios, naquele tempo,/ Eu era um pouco indomável, você queria que eu fosse dócil/ Eu era um pouco feiticeira, você queria que eu fosse Melusine/ Eu me lembro de ti/ Dos teus suspiros enfermos/ Lá, em Marienbad/ Em Marienbad/ Mas, então, onde está você?/ Onde estão seus olhos de jade?/ Tão longe de Marienbad,/ Bem longe de Marienbad/ Mas se você me chamar, em um tempo futuro,/ em um lugar onde nossos caminhos se cruzem, para conversar um instante/ Fique sabendo, eu mudei, porém eu sou como antes/ Do mesmo jeito que me fez, me tornou, e me desfez o tempo/Guardo, junto a mim, a estola de plumas/ As grandes luvas de seda negra e o anel de diamante./ Irei ao seu encontro/ No grande castelo de jade/ No coração de seus labirintos/ Lá, em Marienbad, nós dançaremos ainda/ loucas danças/ Olhando os teus olhos de jade,/ Lá, em Marienbad/ Com teus olhos de jade/ Nós dançaremos ainda,/ Lá, em Marienbad,/ Lá, Marienbad,/ Mas tu regressarás para mim/ No grande castelo de jade,/ Em Marienbad.
\end{abstract}


Na mesma folha de papel, com o trecho da canção, a frase "Aos caminhos, eu entrego o nosso encontro" dá esperança e ânimo ao narrador em sua peregrinação por um reencontro com K. A estrofe da música transcrita na novela também expressa a procura de K pelo narrador e a sua necessidade de encontrá-lo mesmo sem saber onde ele está. Os olhos de jade referidos nos versos revelam-se também pertencentes ao próprio narrador.

\begin{abstract}
Afasto o rosto do vidro da janela do trem que corre pelo meio dos campos até conseguir ver minha imagem refletida. Embora as formas sejam vagas, trêmulas, mais diluídas ainda pela luz do crepúsculo que tomba, posso ver meus dois olhos flutuando no espaço. E apesar das sombras sinuosas que se dobram dentro deles, feito enguias num aquário pequeno demais, confirmo que são muito verdes. Como se fossem de jade. (op.cit., p.43)
\end{abstract}

Além da menção aos "olhos de jade", a última frase do texto de Caio F. faz referência à presença de castelos, como na canção, reforçando a possibilidade de reencontro em um tempo futuro, em que os caminhos das personagens possam se cruzar.

Lá fora, o voo de um grande pássaro quase totalmente branco, talvez uma gaivota, corta minha imagem refletida na vidraça.

Desvio o rosto, não devo me deter tempo demais em meus próprios olhos. Aumento o som da canção, olho para fora enquanto o trem dispara sobre os trilhos. Preciso ficar sempre atento. Ainda não anoiteceu, e alguns dizem que há castelos pelo caminho. (ABREU, op. cit., p. 43)

A canção, no texto, é o elemento que une o passado, o presente e o futuro das personagens. É ela que enfatiza a história comum entre K e o narrador, apontando uma perspectiva através da incerteza do tempo ainda por vir. 0 tempo, cronológico e psicológico, também por sua ausência, é um dos temas centrais do texto. “O tempo dos alvoreceres", mencionado nos versos de Barbara e caracterizado por um período de paixão e de juventude, cede espaço ao tempo do regresso, do amadurecimento, pois as personagens são o que o tempo delas fez. Assim como a personagem do filme $O$ ano passado em Marienbad dá o seu "sim" para a aceitação de um passado e também de um futuro, a canção e a novela fazem o mesmo, ressaltando em seus desfechos a crença no encontro. 
"Marienbad" é uma chave de leitura para a novela, pois acrescenta reflexões para que compreendamos as relações textuais e a relação entre as personagens. Caio Fernando Abreu é um autor que costuma fornecer uma série de indicações extraliterárias que contribuem não só para a apreensão das obras em toda a sua complexidade, mas também para o enriquecimento cultural e humano do leitor que seguir suas pistas. Ainda, a canção direciona-nos ao universo clássico e mitológico europeu através da menção à lenda de Melusine, metade mulher e metade serpente em algumas representações, ou metade sereia, em outras; às gárgulas da arquitetura gótica francesa e à mitologia greco-romana, a partir das imagens de Apolo, de Pigmaleão e das vestais. Completando o quadro de referências, há a menção a Ofélia, personagem shakespeariana, perdida nos labirintos do amor e da loucura. 0 autor dispõe, também através da música citada, a qual nos remete a outras indicações, de um vasto referencial cultural em sua obra, que engloba desde os clássicos à cultura popular, desde o inusitado ao lugar-comum, e tal ecletismo é uma das principais características da obra de Caio F.

De volta à análise da novela, a condição, ou natureza, de viajante, de estrangeiro, também pode vincular-se a laços efêmeros e transitórios. Ao mesmo tempo em que os personagens negam o comprometimento com relações e territórios fixos, assumem um compromisso com a constante mobilidade da viagem. A ideia de raiz, com que costumamos lidar, pode ser diferente da concepção de um estrangeiro. A raiz, neste caso, encontra-se no deslocamento, na ausência de pátria e de lar, como usualmente os concebemos. 0 cineasta alemão Wim Wenders, cujos filmes, em sua maioria, retratam personagens on the road, afirma que "identity means not having to have a home. Awareness, for me, has something to do with not being at home" (BROMLEY, 2002, p. 73). Assim, vincularmos as ideias de identidade, solo e origem, por exemplo, a conceitos cristalizados e unilaterais é reduzir a natureza humana somente a um modelo, a um comportamento. Ser um "desterrado", como afirma Reinaldo Arenas, pode significar a ausência de um lar, mas também a presença de outro: a estrada, o caminho, a chegada, a partida.

Em “O céu de Lisboa” (Lisbon Story), filme de Wenders de 1994, o engenheiro de som Phillip Winter vai a Lisboa depois de receber um cartão-postal de seu amigo Friedrich pedindo ajuda. Winter viaja ao encontro do amigo, mas quando chega ao endereço determinado, não há vestígio de Friedrich. Seus pertences ainda estão lá, 
juntamente aos trechos do filme que está rodando em Lisboa, porém o cineasta não aparece. 0 mote da novela de Caio e o do filme de Wenders é o mesmo: um amigo vai ao encontro de outro, em um país estranho e, chegando lá, não o encontra.

No início de Lisbon Story, Winter dirige da Alemanha até Portugal e reflete enquanto viaja: "Como é agradável dirigir e não pensar em nada, deixar-se levar pela estrada e pela história. Sim, aqui me sinto em casa. É a minha pátria.” O personagem expressa que a estrada, que a constante mobilidade da viagem, com sua variação de paisagens, rostos e línguas, é a sua pátria, o seu lar. Estar em casa, para ele, significa estar em curso, em movimento, ou seja, transgredindo a ideia que se costuma adotar quando se discutem noções de pertencimento. 0 pensamento de Winter não mostra qualquer desconforto ou impaciência em relação ao "deixar-se levar pela estrada e pela história", pelo contrário, afirma que, somente no momento da viagem, ele está verdadeiramente em casa.

Depois que percebe que Friedrich não aparecerá, Winter começa a descobrir as filmagens do amigo, que são, de algum modo, rascunhos visuais daquilo que o cineasta observa pela cidade de Lisboa. As imagens são acompanhadas de depoimentos de Friedrich não só sobre aquilo que vê e filma, mas também sobre suas concepções cinematográficas, sobre suas dúvidas quanto ao seu trabalho e a sua vida. Em uma das filmagens, Friedrich comenta: “Quem poderia estar pronto para perder-se numa cidade a não ser o solitário?" O personagem explicita sua solidão e a caracteriza como uma qualidade, como um pré-requisito para "deixar-se levar pela estrada e pela história". Julia Kristeva também aponta a solidão como uma das características do estrangeiro. "Adepto da solidão, incluindo a que se sente no meio das multidões" (KRISTEVA, 1994, p. 13). No texto de Caio Fernando Abreu, a solidão leva tanto o personagem-narrador de "Bem longe de Marienbad" quanto K à estrada, um à busca do amor, o outro, ao retorno ao seu verdadeiro lar.

Em outra filmagem, Friedrich esclarece a Winter o porquê de sua ausência e de seu afastamento: “A casa me previne de estar na cidade. Ela cria uma proteção que já não quero". A partir desse momento, Winter compreende o comportamento do amigo que, estando na segurança e na comodidade de sua casa, vê-se privado de viver a cidade e a viagem. A casa, em sua dimensão física e concreta, nesse contexto, representa o confinamento que não permite o usufruto da multiplicidade proporcionada pela 
aventura de andar pelas ruas sem destino certo, sem laços ou preocupações. A casa é o elo concreto com a imobilidade, é o elemento que traduz noções de pátria, raiz e pertencimento, conceitos que foram transgredidos pelos personagens e que, por isso, são negados e abandonados por eles. 0 depoimento de Friedrich endossa a afirmação de Wenders "identity means not having to have a home. Awareness, for me, has something to do with not being at home" e esclarece, em alguma medida, o comportamento dos personagens de Caio Fernando Abreu.

Tanto os personagens do texto quanto os do filme são viajantes solitários, os primeiros em uma busca difusa pelo amor, os últimos em busca de uma nova concepção artística no país estrangeiro. A distância de "casa", para todos eles, é sinônimo de liberdade, aventura e aprendizado.

\begin{abstract}
Não pertencer a nenhum lugar, nenhum tempo, nenhum amor. A origem perdida, o enraizamento impossível, a memória imergente, o presente em suspenso. 0 espaço do estrangeiro é um trem em marcha, um avião em pleno ar, a própria transição que exclui a parada. Pontos de referência, nada mais. (KRISTEVA, 1994, p. 15)
\end{abstract}

E a partir desse "espaço do estrangeiro", o narrador de "Bem longe de Marienbad" segue viagem, pois a estrada é sempre aberta. Ao observarmos um trem em marcha ou um avião no ar, apreendemos apenas um fragmento de seu percurso, que pode levar a inúmeras possibilidades e direções. 0 personagem segue viagem porque o movimento é o prelúdio do encontro, uma vez que não há um final concreto em sua trajetória. Ele aceita a partida de K como algo inevitável e coerente, continuando a sua busca. Segue viagem, ainda esperando reencontrá-lo. No trem, é o narrador que se reencontra, sem um destino definido.

Se pensarmos que o estrangeiro é aquele que está distante de sua identidade e de sua história, exatamente por estar distante de sua pátria e de seu lar, como usualmente aplicamos, não estamos analisando os personagens de Caio Fernando Abreu. 0 narrador, ao final da história, segue seu caminho de viagens sem a consciência de estar em busca do que chamamos de lar ou de raízes. A viagem representa sim a constituição de uma identidade, mas de uma identidade individual, afastada da ideia de origem vinculada à terra, por exemplo. Desse modo, os conceitos de identidade e de história mencionados nesse caso dizem respeito a descobertas subjetivas e individuais, sem ligações maiores 
com o território. Portanto, justifica-se a escolha de uma teoria a qual enfatiza os aspectos psicológicos do indivíduo em detrimento de teorias que priorizam a coletividade histórica, cultural e social.

O texto de Julia Kristeva, norteado pelas ideias de Freud, colabora para desfazer a concepção de que o "estranho", o "outro", o "estrangeiro", independentemente da nomenclatura adotada, está distante do "eu" e, desse modo, passível de seu julgamento e crítica. 0 conceito de gauche, por exemplo, hoje já não mais sustenta o tom pejorativo ou negativo que um dia foi atribuído a ele. Pelo contrário, em alguns meios, aquele que não é, ou que não se diz, gauche, "estranho" ou "estrangeiro", é aquele que carrega a marca do deslocamento, pois o "outro" sempre será apontado, por mais que suas características se modifiquem com o passar do tempo. Mas, de qualquer modo, este trabalho tentou explicitar brevemente tais concepções no texto de Caio Fernando Abreu, demonstrando que não só no nível das abstrações e interpretações subjetivas, por exemplo, novos caminhos devem ser descobertos e valorizados. Afinal, a viagem, a estrada e a história estão sempre abertas.

Viaja-se para esquecer, para lembrar, para buscar algo ou alguém, para desligarse da história de um local e construir outra em um local diverso, para viver uma nova identidade ou para abster-se de todas. Alguns viajam apenas como turistas, outros como estrangeiros. E ser estrangeiro não é somente viver o deslocamento cultural, a consciência do não pertencimento. Ser estrangeiro é exercer um outro olhar sobre o que usualmente se costuma ver. É exercer uma nova perspectiva que questiona o lugar comum sociocultural e também o lugar comum quanto à subjetividade e à individualidade. Por isso a dificuldade de enquadramento, de sistematização de algo que, por mais que se tente aplicar conceitos universais, permanecerá como uma característica individual e contextual. Assim, podemos aplicar a concepção de Kristeva de que o "outro" no "eu" é o "estrangeiro" em nós, por exemplo. Porém, essa é uma das leituras possíveis, uma vez que os personagens de "Bem longe de Marienbad", e também de $O$ céu de Lisboa, ultrapassam a abordagem psicanalítica, mesmo que se apliquem a eles características cosmopolitas. Estabelecem outras noções para conceitos tradicionais, pois por mais que sejam "de lugar nenhum ou de todos os lugares", criam um novo espaço para pensarmos o estrangeiro: aquele que, habituado a viajar, sente-se em casa ao estar distante dela. 0 paradoxo permanece, conciliando ideias distintas para 
compor um todo contraditório e complexo, pois assim como o caminho pode ser linear, ou paralelo a outra história, também pode ser transversal, unindo viajantes e lugares de passagem, onde a duração pode ser apenas uma metáfora.

\section{REFERÊNCIAS}

ABREU, Caio Fernando. Cartas. MORICONI, Ítalo (Org.). Rio de Janeiro: Aeroplano, 2002. . Estranhos estrangeiros. Rio de Janeiro: Agir, 2006. . Um biógrafo da emoção. Porto Alegre: Instituto Estadual do Livro, 1988. Autores Gaúchos: Caio Fernando Abreu, v. 19, p. 03-08, 1988. Entrevista concedida a Vera Aguiar, Charles Kiefer e a Roberto Antunes Fleck.

BROMLEY, Roger. From Alice to Buena Vista: The films of Wim Wenders. Westport: Praeger, 2001.

FOUCAULT, Michel. As palavras e as coisas: uma arqueologia das ciências humanas. Trad. Salma Tannus Muchail. São Paulo: Martins Fontes, 1999.

FREUD, Sigmund. "O estranho". In: Edição standard brasileira das obras psicológicas completas de Sigmund Freud. Rio de Janeiro: Imago, 1987. Vol. 17, p. 275-318.

KRISTEVA, Julia. Estrangeiros para nós mesmos. Trad. Maria Carlota Carvalho Gomes. Rio de Janeiro: Rocco, 1994.

MASINA, Léa. Caio Fernando Abreu. In: SANTOS, Volnyr; SANTOS, Walmor (Orgs.). Antologia Crítica do Conto Gaúcho. Porto Alegre: Sagra Luzzato, 1998.

O CÉU DE LISBOA (Lisbon Story). Produzido por: Madragoa Filmes, Road Movies Filmproduktion. Escrito por: Wim Wenders. Dirigido por: Wim Wenders. Intérpretes: Rüdiger Vogler, Patrick Bauchau. 1 DVD (100 MIN), colorido.

PEN, Marcelo. “Quem tem medo de Caio F.?" In: ABREU, Caio Fernando. Estranhos estrangeiros. Rio de Janeiro: Agir, 2006.

Recebido em junho de 2014.

Aceito em novembro de 2014. 